2019-05-01

\title{
Sensitive individuals are more creative
}

\author{
Bridges, D
}

http://hdl.handle.net/10026.1/12342

10.1016/j.paid.2018.09.015

Personality and Individual Differences

Elsevier

All content in PEARL is protected by copyright law. Author manuscripts are made available in accordance with publisher policies. Please cite only the published version using the details provided on the item record or document. In the absence of an open licence (e.g. Creative Commons), permissions for further reuse of content should be sought from the publisher or author. 


\title{
Sensitive Individuals Are More Creative
}

\author{
David Bridges*\#1,2, Haline E. Schendan*1
}

$*=$ joint primary authors

\# corresponding author

${ }^{1}$ Cognition Institute, School of Psychology, University of Plymouth, Plymouth, UK

${ }^{2}$ School of Psychology, University of Nottingham, Nottingham, UK

Conflict of Interest: The authors declare no competing financial interests.

Author 1: David Bridges, School of Psychology (Faculty of Health \& Human Sciences),

Plymouth University, Cognovo, 3rd Floor Link building, Drake Circus, Plymouth, Devon, PL4

8AA, Tel: 07738283216. E-mail: david.bridges@plymouth.ac.uk.

School of Psychology, University of Nottingham, Nottingham, UK, NG7 2RD. E-mail:

\section{david.bridges@nottingham.ac.uk}

Author 2: Haline E. Schendan, School of Psychology (Faculty of Health \& Human Sciences), Plymouth University, Room A208, Portland Square, Drake Circus, Plymouth, Devon, PL4 8AA.

Tel: +44 1752 584804. E-mail: haline.schendan@plymouth.ac.uk.

Manuscript accepted on 11 September 2018 for publication in: Personality and Individual

\section{Differences}

Article Type: SI: Creativity

Section/Category: Review Article ( $<10,000$ words)

Keywords: Personality; Temperament; Sensitivity; Creativity; Plasticity; Cognition; Affect 


\begin{abstract}
Individual differences in cognition, affect, and personality have been explored extensively as factors in creativity, but pinpointing the exact factors has remained elusive. This review proposes that a major gap has been lack of research on the relation between creativity and temperament, which captures the biologically-based core of personality, especially studies on sensitive temperament. Sensitivity has been associated with creativity anecdotally and in early work but rarely investigated recently, particularly using recent more precise definitions of sensitivity and state-of-the-art sensitivity and creativity assessments, nor has the relationship between creativity and cognitive processes that should reflect sensitive neural processing been investigated. This review also aims to identify cognitive abilities that characterize sensitivity and their implications for creativity, concluding that orienting sensitivity is the most important trait in the multiple trait temperament of sensitivity that predicts higher creativity. Sensitive, open people are more creative due to a complex interplay of multiple traits and their associated biological pathways, which originate from plasticity genes that interact with environmental and experiential contexts to influence development of neurotransmitter systems, neurosensitivity mechanisms (especially lower inhibition), and brain networks for automatic attention and orienting.
\end{abstract}


People differ widely in creative ability (Runco, 2014; Sawyer, 2012). Individual differences in cognition, affect, and personality have been explored extensively as factors in creativity, but pinpointing the exact factors has remained elusive (Sawyer, 2012). A creative personality exists (Feist, 1998, 2010), and the "Big-Five" personality traits have various relationships with creativity with openness to experience as the strongest predictor, but controversies remain (Feist, 2010; Kaufman et al., 2016; Runco, 2014; Sawyer, 2012). Sensitivity is a biologically-based personality/temperament dimension (Evans \& Rothbart, 2007; Pluess, 2015a) that has been associated with creativity anecdotally but rarely investigated and with mixed results (Brodsky \& Brodsky, 1981; Martindale, 1999; Martindale, Anderson, Moore, \& West, 1996; Necka \& Hlawacz, 2013; Shamay-Tsoory, Adler, Aharon-Peretz, Perry, \& Mayseless, 2011). Critically, recent state-of-the-art sensitivity and creativity assessments have not been used, especially those reflecting recent advances in defining sensitivity (Aron \& Aron, 1997; Evans \& Rothbart, 2007, 2008; Pluess, 2015a) nor has the relationship between creativity and cognitive processes that should reflect sensitive neural processing been investigated. This review addresses these major gaps in understanding individual differences in creativity, focusing on sensitivity and its implications for cognitive processes supporting creative potential and achievement.

\section{Creativity}

\section{Neurobiological Theories of Creative Cognition}

Neurobiological theories of creativity combine fields of neurobiology, neurogenetics and cognitive neuroscience to explain individual differences in creative ability (Kaufman, Kornilov, Bristol, Tan, \& Grigorenko, 2010). A complication for any theory of creativity involves it's operationalization, as past definitions of creativity have been ambiguous and elusive, offering 
little consistency (Plucker, Beghetto, \& Dow, 2004; Runco \& Jaeger, 2012; Simonton, 2012). However, the consensus "standard definition of creativity" requires both "originality" and "effectiveness" (Runco \& Jaeger, 2012; cf. Simonton, 2016). Originality requires something to be novel. Effectiveness requires an idea or product to be useful. Neither term alone is sufficient for creativity to emerge. For example, original ideas can stem from psychopathology or randomness, but may lack value. On the other hand, effective or useful ideas lacking originality are not new, and so already exist. Relevant to differential psychologists are the influential frameworks that examine how novelty and effectiveness emerge as a function of product, place, process and person (for a review of the Four P's of creativity, see Kozbelt, Beghetto, \& Runco, 2010). Following these approaches, products and place examine creative products and places they flourish, whereas process and person advance the idea that creative ability emerges from basic human cognition, recognizing that individual differences explain all variation in creative ability (Smith, Ward, \& Finke, 1995). In this review, we take a person and process approach from a neurobiological perspective to examine how individual differences in biologically-based temperaments shape personality and creative cognition.

In early work, Martindale (1999) theorized that highly creative people have lower cognitive inhibition due to frontal lobe deactivation, with greater disinhibition in the right hemisphere, but only when engaged in the creative process. More recently, Kaufman et al. (2010) suggest that cognitive disinhibition and hemispheric asymmetry reflect two separate stages of the creative process. Disinhibition allows usually-inhibited, seemingly irrelevant information to enter conscious awareness, thus facilitating the formulation of novel associations (Carson, 2014) that are detected with right-hemisphere lateralized attention mechanisms. The cognitive disinhibition and hemispheric asymmetry hypotheses are major theories of creativity 
that are consistent with evidence linking the creative process with anti-correlated active task (frontoparietal control, salience) and default mode networks (DMN) in the brain (Buckner, Andrews-Hanna, \& Schacter, 2008) that are responsible for externally and internally directed cognition, respectively (Dixon, Fox, \& Christoff, 2014). The DMN contributes to both disinhibition (e.g., Takeuchi et al., 2011) and right hemisphere processes underlying creativity, including exogenous attention (Corbetta \& Shulman, 2002; Friedman, Fishbach, Förster, \& Werth, 2003; Posner \& Rothbart, 2007) and global processing (Förster \& Dannenberg, 2010; Ivry \& Robertson, 1998; Kaufman et al., 2010; Schooler \& Melcher, 1995). This review explains how individual differences resulting from biological dispositions (i.e., temperaments) result in a greater tendency towards those disinhibited and diffused attentional states that are conducive with higher creativity.

\section{Temperament, Personality and Creativity}

\section{Personality and Creativity}

The personality approach to creativity looks for stable characteristics or constellations of traits interacting with cognitive and environmental factors that facilitate creativity (Runco, 2014). The personalities of creative people are complex and paradoxical. For example, creative people may have higher levels of intelligence but the naivety to question, the extraversion to exchange ideas but the solitary introversion to work, the ability to engage in imagination/fantasy but keep ideas rooted in reality, and an openness and sensitivity to experience consciousness but a resilience so as not to suffer (Csikszentmihalyi, 1996). A quantitative meta-analysis shows the most creative individuals are more likely to be higher in openness, introversion, impulsivity, and display higher sensitivity to internal affective states compared with less creative people, but this differs between artists and scientists (Feist, 1998); see also Batey and Furnham (2006). 
Openness is the factor amongst the Big-Five personality dimensions with the strongest relationship with creativity (Feist, 2010; Kaufman et al., 2016; Runco, 2014; Sawyer, 2012). Openness is a universal dimension of personality characterized as "the breadth, depth, and permeability of consciousness, and in the recurrent need to enlarge and examine experience" (McCrae \& Costa, 1997, p. 826), the tendency to be imaginative, curious, perceptive, creative, artistic, thoughtful and intellectual, all subsumed under the overarching explanation of cognitive exploration (Deyoung et al., 2011). An Openness/Intellect personality captures core but distinct elements of a global domain, referring to engagement with perceptual (for openness) and abstract (for intellect) information (Deyoung et al., 2011), but including intelligence within the Openness/Intellect factor is controversial, as is the suggestion that creativity is synonymous with Openness/Intellect (Deyoung, 2013; Johnson, 1994). Indeed, whilst self-reports of openness are weakly positively correlated with divergent-thinking (McCrae, 1987; Silvia, Nusbaum, Berg, Martin, \& O'Connor, 2009) and moderately positively with real-world creative achievements (Carson, Peterson, \& Higgins, 2005; Silvia et al., 2009), discriminant validity is suggested (rs $<.85$; Kline, 2015). Openness, however, may interact with a range of other creative characteristics, including autonomy, unconventionality and sensitivity (Runco, 2014); note, in this idea, sensitivity is defined informally and does not use current definitions.

Big-Five traits converge to form higher-order meta-traits of "plasticity" and "stability", providing a missing link between child development and adulthood by defining core constitutional mechanisms that "grow" personality through social and environmental interactions (DeYoung, Peterson, \& Higgins, 2002, 2005; Digman, 1997; see also Evans \& Rothbart, 2009; Rothbart, 2007). Plasticity and stability are related to, but have opposing effects (positive vs. negative relationship, respectively), on measures of divergent-thinking (Silvia et al., 2008) and 
creative achievement (Silvia et al., 2009): Only plasticity predicts higher creativity. Stability loads neuroticism (reversed), conscientiousness and agreeableness and is related to serotonergic variation underlying emotional and motivational regulation, and controlled, organized, goaloriented behavior (DeYoung et al., 2006). Plasticity loads openness and extraversion traits. Extraversion is a behavioural manifestation of exploratory, approach behaviours and reward seeking and is considered distinct from the more cerebral cognitive exploration of Openness/Intellect. However, the commonalities between these two traits can be explained by the influence of dopamine forming a biological substrate for both (Depue \& Collins, 1999; Deyoung et al., 2011; DeYoung et al., 2002, 2005). Variation in both D4 (DRD4) and catecholO-methyl-transferase (COMT) genes involved with prefrontal dopaminergic function predict Openness/Intellect, and DRD4 also predicts Extraversion (Deyoung et al., 2011), consistent with a biological taxonomy perspective that personalities are composed of interdependent, contingent, and multiple-level traits, instead of independent factors (Trofimova, Robbins, Sulis, \& Uher, 2018).

\section{Temperament and Personality}

Despite numerous studies, the existence of a relationship between creativity and personality traits remains controversial (Necka \& Hlawacz, 2013; Sawyer, 2012) so this review proposes that the sometimes tenuous evidence for a relationship is due to factors not adequately captured by psychometric personality assessments: Temperaments (Necka \& Hlawacz, 2013). These are early emerging basic dispositions in activity, affectivity, attention and self-regulation due to a complex interaction of genetic, epigenetic, biological and environmental factors that form the foundations of global personality traits (Goldsmith et al., 1987; Rothbart, Ahadi, \& Evans, 2000; Shiner et al., 2012). Some argue that temperament and personality are different 
ways of describing the same trait separated only by the age of manifestation, with temperament relating to childhood and personality relating to adulthood. In this view, individual differences in temperament are subsumed under the Big-Five traits (Shiner et al., 2012; Shiner \& DeYoung, 2013). However, there is consensus that core properties of personality and temperament are distinct. Personality concerns a wide range of individual differences interacting with sociocultural factors, including specific thoughts (i.e., cognitions, beliefs, values). Temperament includes dispositional biological and cognitive processes relating to reactivity and regulation (e.g., arousal and attention orienting) that interact with socio-cultural factors, and influence, but do not include, specific thoughts, most of which are specific to humans (Evans \& Rothbart, 2007; Trofimova \& Robbins, 2016).

A key difference between temperament and personality models rests in how those constructs are defined empirically. Temperament theories have a biological basis, for example explaining human behavior as a complex interplay between specific neurotransmitter systems (Trofimova, 2018). Personality models, such as the Big-Five, are constructed based on the lexical hypothesis, which assumes all important human personality attributes will be encoded in languages across the world, ultimately as single terms (Goldberg, 1993). Indeed, the Big-Five personality model is based on correlations and factor analysis emerging from peer ratings (cf. McCrae \& Costa, 1987), taking a structural approach looking for consistency (e.g., across cultures) in broad, universal traits, rather than change, being unconcerned with how measures on a particular personality dimension have developed, i.e., how biological dispositions grow personalities through experience (Trofimova, 2018). The lexical approach has been criticized, for example, as being affected by pro-social bias of language, meaning that peer ratings are biased towards the socialization aspects of human life, rather than the biological factors of individuality. 
Further, the statistical approaches used to define dimensions of personality (i.e., correlations and factor analysis) are not sufficient to capture the dynamical, interactive relationship between components of biologically-based traits (Trofimova, 2014). In this paper, we argue that the controversial link between creativity and personality (Necka \& Hlawacz, 2013; Sawyer, 2012) exists because the lexically-driven models of personality do not adequately capture the biologically-based individual differences that may explain individual creativity.

Temperament has received little attention in creativity literature and is not explicitly included in recent influential reviews and books (Hennessey \& Amabile, 2010; Kaufman \& Sternberg, 2010; Sawyer, 2012) and models of the creative personality (Feist, 2010), though it is indirectly included by acknowledging genetic and epigenetic influences on creativity and has recently been identified as a major critical gap in creativity research (Feist, 2010; Necka \& Hlawacz, 2013; Runco, 2014).

\section{Early Studies of Creativity and Sensitivity}

Sensitive temperament has been associated with creativity mainly based on anecdotal observations, "every sensitive person is unusually creative" (Shamay-Tsoory et al., 2011, p. 104), in qualitative research characterizing eminent creators (Martindale, 1989; Runco, 1998) or groups (Brodsky \& Brodsky, 1981), and in a few early experiments where Martindale and colleagues highlighted the role of sensitivity or reactivity of cortical arousal in creative cognition, showing that highly creative people are over-sensitive and more physiologically reactive than people low in creativity (for a review, see Martindale, 1999). The latter provided the first experimental evidence that physiological sensitivity and slower habituation of the attention orienting response is linked to creative potential. In summary, Martindale and colleagues found that high, compared to low creativity, is associated with higher automatic alpha 
blockade (switching to externally-directed endogenous attention) during the course of auditory habituation, and higher intentional alpha suppression (Martindale \& Armstrong, 1974). Alpha occurs when a person is minimally aroused; relaxed but awake. Greater alpha activity is thought to indicate the low arousal state associated with internally-oriented attention required for associative ideation (cf. Dietrich \& Kanso, 2010; Fink \& Benedek, 2014; Martindale \& Armstrong, 1974). Further, high, compared to low creativity, is associated with higher ratings of electric shock intensity (i.e., higher sensitivity) (Martindale, 1977), increments in skin conductance response instead of decrements (i.e., higher automatic orienting attention), and less gamma electroencephalogram habituation (i.e., higher attention orienting and conscious perception) (Martindale et al., 1996). Overall, this suggests high creativity is associated with both higher automatic attention orienting in the DMN and conscious, effortful, externallydirected attention, consistent with the dynamic interplay between attention networks associated with creativity (Beaty, Benedek, Silvia, \& Schacter, 2016), but also higher sensory sensitivity more precisely defined in recent temperament frameworks.

\section{The Sensitive Temperament}

This review addresses major gaps in creativity and personality research: recent advances in defining the sensitive temperament (Aron \& Aron, 1997; Evans \& Rothbart, 2007; Pluess, 2015a). Sensitivity is often measured using the inventory approach (Aron, Aron, \& Jagiellowicz, 2012; Evans \& Rothbart, 2007; Strelau \& Zawadzki, 1993) although the trait is proposed to have a biological-basis (e.g., Aron \& Aron, 1997) and thus falls within the definitions of temperament defined in this review. Different temperament frameworks provide unique but overlapping explanations of sensitive temperaments, although the relationship between individual differences in creativity and current definitions of sensitivity, as well as the cognitive processes that should 
reflect sensitive neural processing, have not been considered together prior to this review. Space does not permit a thorough review of the biological foundations and neural correlates of sensitivity, however for a broadly focused review of the biological substrate of sensitivity, see Moore and Depue (2016), and see Homberg, Schubert, Asan, and Aron (2016) for an examination of the similarities between SPS and short (s) low-expressing allelic variant of the serotonin transporter linked polymorphic region (5-HTTLPR) and the proposed underlying neur(on)al mechanisms of neurosensitivity. Based on an integration of sensitivity frameworks, this review focuses on sensitivity to propose its neurocognitive implications for creativity.

\section{Temperament Frameworks Highlighting Sensitivity}

Sensory-sensitivity. In 1993, Strelau's Regulative Theory of Temperament defined a biologically-based temperament taxonomy according to individual differences in central-nervoussystem properties. Strelau and Zawadzki (1993) proposed six temperament traits, including "sensory-sensitivity" defined as how easily one reacts to sensory stimulation of low stimulus value (Hintsa et al., 2016; Kantor-Martynuska, 2012). Data-driven approaches suggest higher sensorysensitivity produces faster responses to low than high threshold stimulation, but the methods used have questionable reliability and validity (for a review, see Strelau, 1998). Strelau addressed the shortcomings of the data-driven approach by defining temperament in terms of temporal and energetic (i.e., arousal level) behavioral characteristics and developing the Formal Characteristics of Behaviour-Temperament Inventory. Using this inventory, Strelau and Zawadzki (1995) show sensory-sensitivity trait positively correlates with Openness, suggesting a role for sensorysensitivity in creative personalities (e.g., Bridges \& Schendan, submitted). However, the underlying mechanism of sensory-sensitivity measured with the inventory approach cannot be answered, and may result from either sensory thresholds or orienting attention (Strelau \& 
Zawadzki, 1995). Further, the sensory-sensitivity scale has low validity scores and has been excluded from recent studies (Hintsa et al., 2016), and the Regulative Theory of Temperament scale has not been used to study creativity. Sensory-sensitivity has been suggested to need revision to incorporate multimodal, emotional and attention implications highlighted by more recent temperament frameworks (Kantor-Martynuska, 2012), described next.

Sensory-processing-sensitivity (SPS). In 1997, SPS (Aron \& Aron, 1997) was defined as a broad temperament consisting of sensitivity traits associated with different outcomes in personality, well-being and creative potential (Aron \& Aron, 1997; Smolewska, McCabe, \& Woody, 2006; Sobocko \& Zelenski, 2015). It is a unidimensional genetically influenced trait characterized by differences in transmitting and processing sensory information. People with high sensitivity tend to be more inhibited towards novelty, but show greater openness to environmental subtleties and engage in deeper processing strategies for planning effective action, all driven by stronger biological or emotional reactivity (Aron \& Aron, 1997; Aron, Aron, \& Davies, 2005; Aron et al., 2012). The self-report, highly sensitive person scale (HSPS) was designed to measure this temperament as a unidimensional construct by Aron and Aron (1997), although they originally identified two distinct groups of highly sensitive individuals differing in their manifestations of negative affect following experiences of contextual adversity (e.g., childhood trauma). Indeed, recent evidence supports the existence of a multiple trait structure to the HSPS consisting of one global, higher-order domain of sensitivity and up to three moderately positively correlated traits: Aesthetic- or orienting-sensitivity (OS; i.e., aesthetic awareness or automatic attention orienting to subtle stimulation, respectively) is the most commonly found; a negative-affect (NA) trait, which most studies indicate is composed largely of at least two traits: ease-of-excitation (i.e., easily overwhelmed by stimulation) and low-sensory-threshold (i.e., 
unpleasant sensory reaction to external stimulation, e.g., loud noise) (Bridges \& Schendan, submitted; Evans \& Rothbart, 2008; Lionetti et al., 2018; Smolewska et al., 2006; Sobocko \& Zelenski, 2015). Intriguingly, two factor solutions of the HSPS (Evans \& Rothbart, 2008) indicate that OS and NA are differentially related to measures of positive and negative affect, respectively (Evans \& Rothbart, 2008; Sobocko \& Zelenski, 2015), consistent with two distinct highly sensitive groups reported by Aron and Aron (1997). The HSPS distinguishes between those high on HSPS (HSP) versus non-HSP groups, which divide further into medium and low sensitivity groups (Lionetti et al., 2018). These three groups differ in relative sensitivity but not relative composition of HSPS traits, supporting the existence of a global, unidimensional sensitivity domain (Lionetti et al., 2018). However, HSPS traits have different relationships with positive and negative affect, emotional reactivity, and Big-Five personality factors (Bridges \& Schendan, submitted; Evans \& Rothbart, 2008; Lionetti et al., 2018; Smolewska et al., 2006; Sobocko \& Zelenski, 2015), suggesting each may be associated with different developmental outcomes.

Emotion-attention temperament framework. OS and NA traits are captured within the emotion-attention framework of Evans and Rothbart, which defines four temperament factors based on emotion and dispositional attention. These temperaments are measured using the selfreport, Adult Temperament Questionnaire (ATQ; Evans \& Rothbart, 2007, 2008, 2009) that expands measurements of OS and NA traits identified in two-factor solutions of the HSPS, but treats them as two independent temperaments (Evans \& Rothbart, 2008) that are distinct from "effortful-control" and "extraversion" temperaments, which are not HSPS traits (Evans \& Rothbart, 2008). OS is defined as automatic orienting attention to internal and external events and relates to exogenous involuntary, stimulus-driven attention in the ventral (posterior) network 
that aligns attention externally to relevant sensory stimulation (Connor, Egeth, \& Yantis, 2004; Corbetta \& Shulman, 2002; Posner \& Rothbart, 2007) or internally to explicit memory (Binder \& Desai, 2011; Buckner et al., 2008), as described in the attention to memory model (Cabeza et al., 2011). OS is distinct from effortful control, or endogenous, voluntary, goal-driven orienting of attention controlled by dorsal (anterior) attention networks (for a review, see Rothbart, Derryberry, \& Posner, 1994). OS is the positive-affect-related component with strong positive correlations with openness. NA relates to negative feeling, over-arousal and sensory discomfort and is the negative-affect-related component correlated positively with neuroticism and introversion (Bridges \& Schendan, submitted; Evans \& Rothbart, 2008; Sobocko \& Zelenski, 2015). This framework adds unique value by characterizing OS according to variation in an observable, objective cognitive ability of automatic attention and orienting.

Environmental sensitivity: For better or worse. The environmental sensitivity (ES), framework incorporates ideas about SPS (Aron \& Aron, 1997), explaining both negative and positive aspects of sensitivity within a single account (Pluess, 2015a): Disproportionate reactivity to the environment can produce either negative outcomes (e.g., neuroticism, introversion, anxiety) due to history of contextual adversity (Aron \& Aron, 1997; Aron et al., 2005; Pluess, 2015a), or "vantage sensitivity" wherein positive outcomes (e.g., openness, resilience, creativity) arise from a history of contextual advantage (or enriching environments, e.g., sensitive parenting) (Pluess, 2015b). The HSPS captures both outcomes, as indicated by its two- and three-factor solutions (Evans \& Rothbart, 2008; Smolewska et al., 2006; Sobocko \& Zelenski, 2015). Individual variations in gene-environment interactions, epigenetics, and associated neurobehavioral phenotypes (e.g., temperament traits) result in greater environmental reactivity (Belsky \& Pluess, 2009; Pluess, 2015a). ES is polygenic, including the 5-HTTLPR and DRD4 7- 
repeat or DRD2 of dopaminergic genes (Homberg et al., 2016; Moore \& Depue, 2016). The clearest evidence shows that high HSPS scores are associated with s/s homozygosity of 5HTTLPR (Licht, Mortensen, \& Knudsen, 2011) and multiple candidate genes affecting the dopaminergic system (Chen et al., 2011). ES is proposed to be grounded in a "neurosensitivity" mechanism in which the central-nervous-system responds more strongly to sensory stimulation in more sensitive individuals (Pluess, 2015a). At the neuronal level, the mechanism for both ES and 5-HTTLPR has been proposed to be neuronal hyper-excitability due to reduced inhibitory control and increased synaptic spine density, providing a mechanism whereby stimulation accumulates to threshold levels more rapidly in sensitive individuals (Homberg et al., 2016). Cognitive disinhibition (i.e., reduced inhibition) is a key mechanism for the creative process (Kaufman et al., 2010; Martindale, 1999) and may contribute to the relationship between higher creativity in sensitive people (Figure 1).

Plasticity (sensitivity) temperament. A recent temperament taxonomy linked traits with sets of neurotransmitters, as in the Functional Ensemble of Temperament (FET; Trofimova \& Robbins, 2016). While FET does not explicitly name a sensitive temperament, the mental trait of Plasticity (vs. rigidity) captures this concept, by referring to variation in ease of starting and stopping activity and flexibility and adaptability to new contexts and is associated with frontal lobe function (Trofimova, 2010). Consistent with this, plasticity in FET is associated with serotonin (5HT) neurotransmitter systems and dopamine (especially DRD4) (i.e., plasticity genes) that have been implicated in ES. Further, while general arousal, which is central to most temperament theories, has been associated with extraversion personality, FET and ES frameworks agree that general arousal confounds the low sociability of introverts and high sensitivity, and the arousal 
systems underlying ES, sociability, and impulsivity differ (Aron et al., 2012; Trofimova \& Robbins, 2016).

A synthesis of sensitivity frameworks. Crucially, all these major temperament frameworks include sensitivity as a major domain of trait facets and the substantial feature overlap allows synthesis into a parsimonious understanding of sensitivity.

Each framework defines sensitivity as reactivity to environmental stimuli, where thresholds are defined by the interaction between the trait magnitude of neurosensitivity, and the magnitude of the environmental stimuli, which further interact with emotional-motivation systems that trigger adaptive behaviours of approach or avoidance, depending on the valence of the emotional response to the environment (Moore \& Depue, 2016; Pluess, 2015a) Stimulation beyond sensory-threshold experienced with high sensitivity can lead to positive or negative-affect-related outcomes and tendencies, depending on how developmental context interacts with plasticity genes (Aron \& Aron, 1997; Pluess, 2015a; Trofimova, 2010). The needs and capacity system in FET theory provides a mechanism explaining how happiness or suffering is dependent on an organisms capacity to cope with events that trigger overstimulation (Trofimova, 2018). When needs outweigh capacity, the resulting affective valence is negative, and when capacity is sufficient to cope with need, the resulting valence is positive. This is particularly important in relation to novelty, a core requisite of creativity (Runco \& Jaeger, 2012), considering that novelty presents potential for uncertainty, un-preparedness and incapacity to cope. Overstimulation from novelty experienced by high sensitives may signal lack of capacity to handle situations, resulting in behavioural inhibition and withdrawal (Aron \& Aron, 1997). This tendency, however, is mediated by experiential context interacting with plasticity genes during development. Traumatic environments develop tendencies towards negative-affect, withdrawal and avoidance of novelty (Aron \& Aron, 
1997; Aron et al., 2005), and beneficial, enriching environments develop tendencies towards positive-affect, openness and resilience of vantage sensitivity (Pluess, 2015b), which are important for creativity (Csikszentmihalyi, 1996). The ability to cope (or not) with sensory overload may influence cognitions in similar ways by upregulating the alerting and orienting systems (i.e., higher orienting sensitivity) to find additional alternatives that a) help cope in cases of negative-affect, or b) challenge existing capacities in cases of positive-affect thus enabling greater capacity for sensation (information) seeking (Trofimova, 2018).

As we shall see, these cognitive implications may define the sensitive creator as one outcome of vantage sensitivity. However, to fully understand sensitivity may require an interdisciplinary approach based on empirically-supported, biological concepts to define traits, rather than the lexically-driven approach of personality psychology to define independent traits, such as the Big-Five (Trofimova et al., 2018). The biological taxonomy perspective, exemplified by FET, does not require independent traits but instead suggests that traits are composed of interdependent, contingent, and multiple-level characteristics (Trofimova et al., 2018) that should be measured together, where multiple-trait configurations describe each individual (Cloninger \& Zwir, 2018; Kagan, 2018), e.g., in studies identifying creative personalities. By this view, sensitivity (by any framework) may be better characterized as a multi-trait profile instead of a single temperament trait. Indeed, the multiple-factor nature of the HSPS supports this view, as the HSPS was designed to capture a particular type of person characterized by a set of traits (Aron \& Aron, 1997; Aron et al., 2012; Lionetti et al., 2018). In contrast, the emotion-attention framework with the ATQ, defines independent temperaments, proposing that OS traits define sensitive temperament, whereas other HSPS traits contribute to an NA temperament. However, according to the ES view and a multiple trait view of temperament, a global sensitive temperament may be 
characterized by sets of either OS and NA traits in the emotion-attention framework or the multiple traits of the HSPS (OS, ease-of-excitation and low-sensory-threshold). Thus a highly sensitive person could have the multiple-trait profile wherein each trait differs in its relationship to personality and creativity.

\section{Mechanisms of Creative Potential and Achievement due to Sensitive Temperaments}

Sensitivity and creativity within modern sensitivity frameworks. A few studies used these recent temperament frameworks to determine a relation between sensitivity and creativity. Plasticity (Sensitive) Temperament in FET is related to divergent-thinking, but its relationship with Big-Five personality factors is unclear. According to Rusalov and Trofimova (2007) plasticity and ergonicity scales of the Structure of Temperament Questionnaire (STQ), which is based on the FET theory, correlate positively with Big-Five extraversion scales (Rusalov, 1989) and the Torrance nonverbal tests of creative thinking, which also correlates negatively with the Emotionality STQ scale (Rusalov \& Poltavtseva, 1997). However, plasticity and ergonicity do not correlate with openness, which instead correlates positively with STQ scales of Empathy, Sensitivity to Probabilities, Intellectual Endurance, and Impulsivity. This illustrates ambiguity in how different sensitivity components are related to each other and to different creativity processes, an important area for future studies of temperaments and creativity.

How different components of the sensitive temperament are related to creativity has not been explored, except for a recent study by Lin and colleagues using the ATQ (2013) and our recent work using both ATQ and HSPS (Bridges \& Schendan, submitted). For activating mood states (approach vs. avoidance), positive-affect is associated with higher creativity, whereas negative-affect is associated with lower creativity (cf. Akinola \& Mendes, 2008; De Dreu, Baas, \& Nijstad, 2008; Kaufmann, 2003). Thus among sensitivity factors, those associated with positive- 
affect (i.e., OS) may increase creativity, while those associated with negative-affect (i.e., NA, or ease-of-excitation and low-sensory-threshold) decrease creativity. Indeed, Lin and colleagues (2013) found that higher ATQ OS predicts verbal and figural insight problem-solving and divergent-thinking subscales of the Abbreviated Torrance Test for Adults (ATTA; Goff \& Torrance, 2002) measuring fluency, flexibility, originality, and elaboration. However, when OS, 6-factor personalities, and IQ are considered altogether, OS explains unique variance in insight but not divergent-thinking subscales (Lin et al., 2013). This suggests that OS is related only to the illumination stage of the creative process (Lubart, 2001; Wallas, 1926) leading to insight. However, NA and the HSPS were not assessed, nor were interactions of sensitivity traits and personality, or overall ATTA score.

More recently, Bridges and Schendan (submitted) conducted a laboratory study with a large diverse sample $(\mathrm{N}=288)$ to establish relationships between sensitivity and creative potential and achievement using state-of-the-art measures. This was done while controlling negative-affect and Big-Five personality traits, which is critical for research on sensitivity due to its conceptual and empirical relationships with openness and negative emotionality including neuroticism and introversion (Aron \& Aron, 1997). Positive associations were demonstrated among three diverse big-C and little-c creativity measures, measuring divergent-thinking (ATTA), ideation (Runco, Plucker, \& Lim, 2000-2001), and achievement (Carson et al., 2005). Critically, only OS and the Big-Five trait of openness positively correlate with all three creativity measures and can each independently predict both achievement and ideation. Intriguingly, OS and openness interact: Openness predicts divergent-thinking and achievement more strongly as sensitivity rises above average. No clear relationship was found between NA sensitivity factors and creativity. Thus, when a multiple-trait profile is considered, OS consistently promotes creativity leading to the 
intriguing conclusion that the positive-affect-related OS component of sensitivity the main one associated with higher creativity and thus vantage sensitivity that promotes creativity.

Genetic basis to the sensitive creator. Sensitive temperament is associated with plasticity genes, especially serotonin and dopamine. Serotonin has a role in cognition, mood, impulse control and motor functions by modulating neuronal activity and neurotransmitter release in regions associated with the DMN (Celada, Puig, \& Artigas, 2013) also implicated in ES (Moore \& Depue, 2016) and creativity [53]. 5-HTTLPR has been associated with verbal and figural creativity (Volf, Kulikov, Bortsov, \& Popova, 2009). Associations between 5-HTTLPR and intelligence raise the possibility of associations in this population between intelligence and creativity. The 5-HTTLPR s-allele is the serotonin gene most strongly linked to ES (Homberg et al., 2016). Short allele (S/S) carriers have higher intelligence scores than those with the long allele (Volf, Sinyakova, Osipova, Kulikova, \& Belousova, 2015). However, sensitivity (ATQ-OS) still predicts insight creativity after controlling intelligence (Raven's) (Lin et al., 2013). This suggests that intelligence cannot entirely explain greater creativity in higher sensitivity. The 5-HTTLPR s-allele is also associated most consistently with increased activity in the DMN, and this activity overlaps with that found in those high on the HSPS (Homberg et al., 2016). Intriguingly, the DMN involvement also supports the ideas that the OS trait captures the primary core of ES (Aron et al., 2012) and underlies individual variation in the involuntary orienting attention system (Evans \& Rothbart, 2007), especially the ventral attention network in the right hemisphere, within the DMN. However, because the ES construct is polygenic, ES effects would be expected in neurotransmitter systems beyond those implicated in the 5-HTTLPR s-allele, especially dopamine, the next most strongly implicated neurotransmitter system. Thus further work will need to disentangle the contribution to 
creativity of cognitive differences associated with sensitivity and its various polygenetic combinations.

Sensitivity, automatic attention, and creativity. The evidence for relationships between sensitivity and creativity, including early behavioural and physiological evidence (for reviews, see Kaufman et al., 2010; Martindale, 1999), supports a role for sensitivity of orienting attention processes in creativity and is consistent with the cognitive disinhibition and hemispheric asymmetry hypothesis of creativity. For example, the Martindale et al. (1996) study indicates that creativity is associated with lower ability to habituate to sensory stimulation, which is associated with a higher orienting response. The orienting response reflects activity in basic motivational systems that function to orient attention immediately towards novel, important and relevant events in the environment, either voluntarily or involuntarily (Sokolov, 1963, 1990) through mechanisms supported by the distributed dorsal and ventral orienting attention brain networks, respectively (Barry, MacDonald, De Blasio, \& Steiner, 2013; Corbetta \& Shulman, 2002; Knight, 1996; Posner \& Rothbart, 2007). The sensitive person is characterized as being more consciously aware of stimuli (Aron et al., 2012), with the OS items of the HSPS and ATQ asking about awareness of subtle information from perceptual, emotional, and memory sources. Intriguingly, disorders of the ventral attention system are associated with low awareness or stimulus insensitivity, as in hemispatial neglect (Friedrich, Egly, Rafal, \& Beck, 1998), although considerable pre-attentive processing of neglected stimuli can still take place without reaching conscious awareness (Driver \& Vuilleumier, 2001). Conversely, high ventral attention function might result in high stimulus sensitivity, as in the sensitive temperament. Although attention may play a critical role in the sensitive and creative person, precisely how OS (Evans \& Rothbart, 2007) and ES (Aron \& Aron, 1997; Pluess, 2015a) map onto endogenous and exogenous 
attention processes has not been established and will be an important area for future work. However, the role of right-lateralized exogenous attention networks in the sensitive creator is implicated since those networks may benefit creativity as global attentional scopes facilitate access to remotely associated content in memory (Förster \& Dannenberg, 2010), which may be useful for global problem restructuring and creative insight (Schooler \& Melcher, 1995) and divergent-thinking (Friedman \& Förster, 2001).

Implications for creativity due to neurosensitivity and attention sensitivity. This review synthesizes these ideas about sensitivity, personality and creativity into a framework of the biological mechanisms that explain why sensitive, open people are more creative (Figure 1).

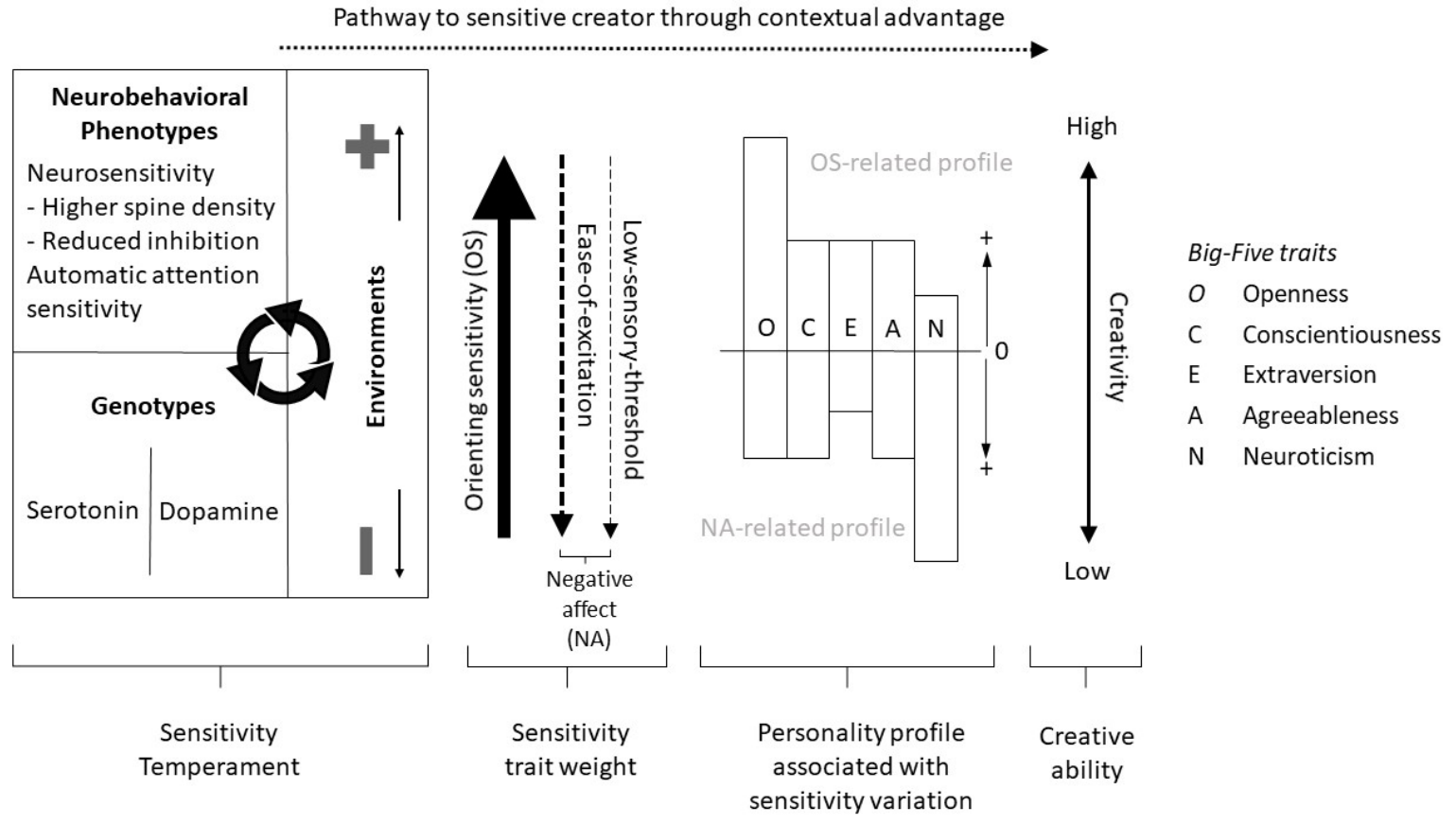

Figure 1. Biological Pathway to the Sensitive Creator. Genotypes (including epigenetics), neurobehavioral phenotypes, and developmental environments shape the outcomes of sensitive temperament. Positive environments (contextual advantage) interact with OS trait to promote resilience to novelty and development of a Big-Five profile with higher Openness thus lowering 
NA traits, or ease-of-excitation and low-sensory-threshold traits, and Neuroticism. Negative environments (contextual adversity) decrease resilience to novelty and probability of a Big-Five profile with lower Openness with higher NA trait (or ease-of-excitation and low-sensory-threshold traits) and higher Neuroticism and, to a lesser extent, lower Extraversion. Consequently, in sensitive temperament, positive environments lead to higher creativity primarily through mechanisms of openness, disinhibition (neurosensitivity via reduced inhibition) and/or resilience and sensitive orienting to novelty, and to a lesser extent, through lower neuroticism. In contrast, negative environments lead, if anything, weakly or possibly even negatively to creativity through mechanisms of lower openness and/or higher negative affect (more neuroticism than introversion) due to lower resilience to novelty and tendencies towards overstimulation (ease-of-excitation; highest association with neuroticism) and higher discomfort from external sensations (lowsensory-threshold). Note. Sensitivity trait weight: Solid arrow indicates strong evidence; dashed arrows indicate weak evidence; line thickness indicates relative strength of association with creativity.

Developmental environment interacting with sensitivity mechanisms define the sensitive creator. The interaction between plasticity genes and the environment influences development of neurobehavioral phenotypes, which embody neurosensitivity mechanisms of reduced inhibition and higher synaptic spine density, as in ES theories, and/or neural mechanisms of automatic attention and orienting sensitivity, in the emotion-attention framework. Intriguingly, these two sets of mechanisms align with the neurobiological account of Martindale (1999), respectively, which suggests that cognitive disinhibition and hemispheric asymmetry reflect two separate stages of creative cognition (Kaufman et al., 2010), including ideation and orientation towards novelty. 
Overall, as a multiple trait temperament, sensitivity promotes creativity, but different sensitivity traits are likely associated with different genes, neurodevelopmental pathways depending upon environmental context, neurobehavioral phenotypes and mechanisms, personality profiles, and creativity processes. Sensitive temperament traits associated with positive affect (i.e., OS) strongly promote higher creativity, while ones associated with negative affect (i.e., NA or ease-of-excitation and low-sensory-threshold), if anything, very weakly increase, or may slightly lower, creativity (e.g., Bridges \& Schendan, submitted). While ES and 5-HTTLPR are clearly associated (Homberg et al., 2016), ES is polygenic, and the HSPS traits are associated with different outcomes in personality, emotion and well-being (Aron \& Aron, 1997; Evans \& Rothbart, 2008; Smolewska et al., 2006; Sobocko \& Zelenski, 2015).

Nonetheless, some mechanisms of neurosensitivity (i.e., cognitive disinhibition/reduced inhibitory control and/or sensitive exogenous orienting) may be common across sensitivity subtypes. Vantage sensitivity may offer greater tolerances for disinhibited thought, exploration, curiosity and openness towards novelty that may be important for creativity. Indeed, the openness and sensitivity to experience consciousness, but with a resilience so as not to suffer, is one of the paradoxical characteristics of the creative person (Csikszentmihalyi, 1996). In vantage sensitivity, due to greater resilience, the need to withdraw for self-regulation due to overstimulation would be lower than in negative-affect-related sensitivity (Aron \& Aron, 1997), thus providing vantage sensitivity a greater range of stimulation and information-extraction that can be used in the creative process (for a review, see Lubart, 2001; Wallas, 1926). See Table 1 for a summary of key insights regarding the effects of sensitivity on underlying biological mechanisms of the sensitive creator. 
Table 1.

Key insights of the underlying biological mechanisms of the sensitive creator

\begin{tabular}{|c|c|c|c|c|}
\hline Genotype & \multicolumn{3}{|c|}{ Phenotype } & References \\
\hline & Neuronal & $\begin{array}{l}\text { Large scale brain } \\
\text { networks }\end{array}$ & $\begin{array}{l}\text { Cognition / } \\
\text { Behaviour }\end{array}$ & \\
\hline \multicolumn{5}{|c|}{ Sensory-sensitivity of the Regulative Theory of Temperament } \\
\hline $\mathrm{n} / \mathrm{a}$ & $\begin{array}{l}\text { Sensory threshold to } \\
\text { low stimulus value }\end{array}$ & $\begin{array}{l}\text { Default mode } \\
\text { network / ventral } \\
\text { attention system }\end{array}$ & $\begin{array}{l}\text { Openness } \\
\text { Sensitive orienting } \\
\text { attention } \\
\text { Susceptibility to } \\
\text { overstimulation }\end{array}$ & $\begin{array}{l}\text { Strelau and } \\
\text { Zawadzki } \\
(1995)\end{array}$ \\
\hline \multicolumn{5}{|c|}{ Plasticity of the Functional Ensemble of Temperament } \\
\hline $\begin{array}{l}\text { Serotonin } \\
\text { (5-HT short } \\
\text { allele) \& } \\
\text { Dopamine } \\
\text { (DRD4) }\end{array}$ & $\begin{array}{l}\text { Enhanced } \\
\text { neuroplasticity }\end{array}$ & $\begin{array}{l}\text { Serotoninergic \& } \\
\text { dopaminergic } \\
\text { neurotransmitter } \\
\text { pathways } \\
\text { interacting, } \\
\text { prefrontal cortex }\end{array}$ & $\begin{array}{l}\text { Ease of } \\
\text { starting/stopping, } \\
\text { adaptability \& } \\
\text { flexibility to novel } \\
\text { contexts, higher } \\
\text { divergent thinking }\end{array}$ & $\begin{array}{l}\text { Trofimova } \\
\text { and Robbins } \\
(2016)\end{array}$ \\
\hline \multicolumn{5}{|c|}{ Environmental sensitivity / sensory-processing sensitivity } \\
\hline $\begin{array}{l}\text { Serotonin } \\
\text { (5-HT short } \\
\text { allele) }\end{array}$ & $\begin{array}{l}\text { Neurosensitivity: } \\
\text { hyperexcitability from } \\
\text { higher spine density } \\
\text { and reduced inhibition }\end{array}$ & $\begin{array}{l}\text { Default mode and } \\
\text { salience } \\
\text { networks, } \\
\text { primarily, \& their } \\
\text { interactions with } \\
\text { cognitive control } \\
\text { network }\end{array}$ & $\begin{array}{l}\begin{array}{l}\text { Susceptibility to } \\
\text { overstimulation }\end{array} \\
\text { Sensitivity to } \\
\text { subtleties } \\
\text { Deeper processing } \\
\text { Higher emotional } \\
\text { reactivity \& empathy }\end{array}$ & $\begin{array}{l}\begin{array}{l}\text { Homberg et } \\
\text { al., (2016) }\end{array} \\
\text { Pluess } \\
(2015 a) \\
\text { Aron and } \\
\text { Aron (1997) }\end{array}$ \\
\hline $\begin{array}{l}\text { Dopamine } \\
\text { (DRD4 } \\
\text { 7-repeat, } \\
\text { DRD2) }\end{array}$ & & $\begin{array}{l}\text { Dopamine } \\
\text { pathways }\end{array}$ & $\begin{array}{l}\text { Lower latent } \\
\text { inhibition }\end{array}$ & $\begin{array}{l}\text { Moore and } \\
\text { Depue (2016) } \\
\text { Chen et al., } \\
\text { (2011) }\end{array}$ \\
\hline \multicolumn{5}{|c|}{ Orienting Sensitivity of the emotion-attention framework } \\
\hline $\begin{array}{l}\text { Proposed } \\
\text { Serotonin }\end{array}$ & Serotonergic cells & $\begin{array}{l}\text { Default mode } \\
\text { network / ventral } \\
\text { attention system }\end{array}$ & 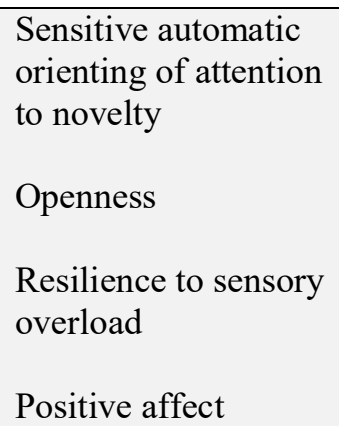 & $\begin{array}{l}\text { Homberg et } \\
\text { al., (2016) } \\
\text { Evans and } \\
\text { Rothbart } \\
(2007)\end{array}$ \\
\hline
\end{tabular}


The four-stage model of creativity (for a review, see Lubart, 2001; Wallas, 1926) breaks the creative process down into separate cognitive processes involving preparation, incubation, illumination and verification. Preparation involves information-gathering, a primary function of the orienting reflex (Posner, 1980; Sokolov, 1963, 1990), and, of particular importance in creativity, would be orientation towards novelty. Novelty-seeking is a behavioral trait associated with positive affect and openness, both of which are OS correlates (DeYoung et al., 2002, 2005; Evans \& Rothbart, 2007; Sobocko \& Zelenski, 2015). A sensitive orienting system in vantage sensitivities, as with OS, would be more able to extract and encode information. During incubation, cognitive disinhibition resulting from low arousal or effortful control could facilitate spontaneous mind wandering, day-dreaming etc., perhaps in part through associated upregulation of automatic exogenous orienting attention in the DMN and ventral attention network, as in OS. During incubation, a sensitive, strongly right lateralized exogenous attention system could have a greater ability to orient towards low threshold, novel associations in memory and bring them to the forefront of consciousness in a spark of insight, or illumination (e.g., Lin et al., 2013). This would predict, for example, higher scores on creative insight tasks such as the remote-associates task. Consistent with this, greater insight in remote-associates task performance is associated with higher alpha electroencephalogram (Jung-Beeman et al., 2004; Kounios et al., 2008) that may reflect right lateralized exogenous attention (Cooper, Croft, Dominey, Burgess, \& Gruzelier, 2003; Klimesch, Doppelmayr, Russegger, Pachinger, \& Schwaiger, 1998) or internally directed cognitions required for associative ideation (cf. Dietrich \& Kanso, 2010; Fink \& Benedek, 2014; Martindale \& Armstrong, 1974). OS may index diffused, exogenous attentional processes associated with global hierarchical perception and could be associated with higher remoteassociates task performance, insight, and divergent-thinking performance (e.g., Bridges \& 
Schendan, submitted; Lin et al., 2013), consistent with the hemispheric asymmetry hypothesis of creativity.

Neurosensitivity with associated plasticity genes and their related neurotransmitter systems could explain higher automatic attention and orienting processes that promote creativity, and may thus explain the biology of sensitive temperament and its relation with creativity. Neural mechanism, including disinhibition and ventral attention in the DMN could be key to explaining the sensitivity and creativity relationship, as suggested by the cognitive disinhibition and hemispheric asymmetry accounts of creativity. The DMN is associated with sensitivity (Jagiellowicz et al., 2010) via exogenous attention thought to underlie the OS. The DMN supports global functional integration, thinking and memory processing (Vatansever, Manktelow, Sahakian, Menon, \& Stamatakis, 2018; Vatansever, Menon, Manktelow, Sahakian, \& Stamatakis, 2015) and is the large scale cortical network most strongly associated with creativity (Beaty et al., 2016). So far, only the OS trait of sensitivity has been clearly associated with creativity (Bridges \& Schendan, submitted; Lin et al., 2013). This review proposes that the OS trait is the most important of sensitivity traits for creativity, and the neurosensitivity mechanisms that promote creativity include disinhibition, automatic orienting, and right hemisphere processes for global processing and integration in the DMN. Nonetheless, future work on sensitivity and creativity should determine whether other sensitivity/plasticity traits, neurotransmitter systems, and genes are associated with creativity. For example, psychopathology has been linked to creativity (Carson, 2014; Carson, 2011), suggesting the negative affect-related traits of sensitivity may also contribute to some processes that underlie creativity.

\section{Future Directions}


We recommend that a broad aim of future research on individual differences in creativity should be to determine individual differences in biologically-based personality and temperament, especially sensitivity traits that characterize the creative person. One aim should be to establish relationships between temperament, personality and creative potential and achievement using a variety of state-of-the-art measures. A second aim should be to establish objective measures of the cognitive, sensorimotor, and socioemotional processes associated with the temperament and personality traits that are associated with creativity to facilitate development of a neurobiological basis for creativity. We recommend focusing on both the global sensitivity temperament and the OS trait, which have received little attention in creativity research, yet temperament is the biologically-based core of personality, and OS is associated with openness, which is the personality most strongly linked to creativity. This review proposes the novel hypothesis that vantage sensitivity especially includes an OS trait that interacts with positive experiences to promote positive outcomes of the sensitive temperament, such as creativity, and thus provides a cognitive basis for the role of sensitivity in creative cognition, through the mechanisms of automatic attention (Evans \& Rothbart, 2007) or, more generally, neurosensitivity of multiple brain systems, including attention systems, and resilience to novelty (Evans \& Rothbart, 2008; Pluess, 2015a, 2015b). 


\section{References}

Akinola, M., \& Mendes, W. B. (2008). The dark side of creativity: biological vulnerability and negative emotions lead to greater artistic creativity. Pers Soc Psychol Bull, 34(12), 16771686.

Aron, E. N., \& Aron, A. (1997). Sensory-Processing Sensitivity and Its Relation to Introversion and Emotionality. Journal of Personality and Social Psychology, 73(2), 345-368.

Aron, E. N., Aron, A., \& Davies, K. M. (2005). Adult shyness: the interaction of temperamental sensitivity and an adverse childhood environment. Pers Soc Psychol Bull, 31(2), 181-197.

Aron, E. N., Aron, A., \& Jagiellowicz, J. (2012). Sensory processing sensitivity: a review in the light of the evolution of biological responsivity. Pers Soc Psychol Rev, 16(3), 262-282.

Barry, R. J., MacDonald, B., De Blasio, F. M., \& Steiner, G. Z. (2013). Linking components of event-related potentials and autonomic measures of the orienting reflex. Int $J$ Psychophysiol, 89(3), 366-373.

Batey, M., \& Furnham, A. (2006). Creativity, intelligence, and personality: A critical review of the scattered literature. Genetic Social and General Psychology Monographs, 132(4), 355-429.

Beaty, R. E., Benedek, M., Silvia, P. J., \& Schacter, D. L. (2016). Creative Cognition and Brain Network Dynamics. Trends Cogn Sci, 20(2), 87-95.

Belsky, J., \& Pluess, M. (2009). Beyond diathesis stress: differential susceptibility to environmental influences. Psychol Bull, 135(6), 885-908.

Binder, J. R., \& Desai, R. H. (2011). The neurobiology of semantic memory. Trends Cogn Sci, 15(11), 527-536.

Bridges, D., \& Schendan, H. E. (submitted). The Sensitive, Open Creator: Sensitive Temperament and Open Personality Predict Creativity.

Brodsky, P., \& Brodsky, M. (1981). A model integrating risk variables involved in the development of the schizophrenia spectrum. J Nerv Ment Dis, 169(12), 741-750.

Buckner, R. L., Andrews-Hanna, J. R., \& Schacter, D. L. (2008). The brain's default network: anatomy, function, and relevance to disease. Ann N Y Acad Sci, 1124, 1-38.

Cabeza, R., Mazuz, Y. S., Stokes, J., Kragel, J. E., Woldorff, M. G., Ciaramelli, E., . . . Moscovitch, M. (2011). Overlapping parietal activity in memory and perception: evidence for the attention to memory model. J Cogn Neurosci, 23(11), 3209-3217.

Carson, S. (2014). Leveraging the "mad genius" debate: why we need a neuroscience of creativity and psychopathology. Front Hum Neurosci, 8, 771.

Carson, S. H. (2011). Creativity and psychopathology: a shared vulnerability model. Can J Psychiatry, 56(3), 144-153.

Carson, S. H., Peterson, J. B., \& Higgins, D. M. (2005). Reliability, validity, and factor structure of the creative achievement questionnaire. Creativity Research Journal, 17, 37-50.

Celada, P., Puig, M. V., \& Artigas, F. (2013). Serotonin modulation of cortical neurons and networks. Front Integr Neurosci, 7, 25.

Chen, C., Moyzis, R., Stern, H., He, Q., Li, H., Li, J., . . Dong, Q. (2011). Contributions of dopamine-related genes and environmental factors to highly sensitive personality: a multi-step neuronal system-level approach. PloS one, 6(7), e21636.

Cloninger, C. R., \& Zwir, I. (2018). What is the natural measurement unit of temperament: single traits or profiles? Phil. Trans. R. Soc. B, 373(1744), 20170163. 
Connor, C. E., Egeth, H. E., \& Yantis, S. (2004). Visual attention: bottom-up versus top-down. Current Biology, 14(19), R850-R852.

Cooper, N. R., Croft, R. J., Dominey, S. J., Burgess, A. P., \& Gruzelier, J. H. (2003). Paradox lost? Exploring the role of alpha oscillations during externally vs. internally directed attention and the implications for idling and inhibition hypotheses. International Journal of Psychophysiology, 47(1), 65-74.

Corbetta, M., \& Shulman, G. L. (2002). Control of goal-directed and stimulus-driven attention in the brain. Nat Rev Neurosci, 3(3), 201-215.

Csikszentmihalyi, M. (1996). Flow and the psychology of discovery and invention. New York: Harper Collins.

De Dreu, C. K., Baas, M., \& Nijstad, B. A. (2008). Hedonic tone and activation level in the mood-creativity link: toward a dual pathway to creativity model. J Pers Soc Psychol, 94(5), 739-756.

Depue, R. A., \& Collins, P. F. (1999). Neurobiology of the structure of personality: Dopamine, facilitation of incentive motivation, and extraversion. Behavioral and Brain Sciences, 22(3), 491-517.

Deyoung, C. G. (2013). The neuromodulator of exploration: A unifying theory of the role of dopamine in personality. Front Hum Neurosci, 7, 762.

Deyoung, C. G., Cicchetti, D., Rogosch, F. A., Gray, J. R., Eastman, M., \& Grigorenko, E. L. (2011). Sources of Cognitive Exploration: Genetic Variation in the Prefrontal Dopamine System Predicts Openness/Intellect. J Res Pers, 45(4), 364-371.

DeYoung, C. G., Peterson, J. B., \& Higgins, D. M. (2002). Higher-order factors of the Big Five predict conformity: Are there neuroses of health? Personality and Individual Differences, 33(4), 533-552.

DeYoung, C. G., Peterson, J. B., \& Higgins, D. M. (2005). Sources of openness/intellect: cognitive and neuropsychological correlates of the fifth factor of personality. $J$ Pers, 73(4), 825-858.

DeYoung, C. G., Peterson, J. B., Séguin, J. R., Mejia, J. M., Pihl, R. O., Beitchman, J. H., . . . Palmour, R. M. (2006). The dopamine D4 receptor gene and moderation of the association between externalizing behavior and IQ. Archives of General Psychiatry, 63(12), 1410-1416.

Dietrich, A., \& Kanso, R. (2010). A review of EEG, ERP, and neuroimaging studies of creativity and insight. Psychological bulletin, 136(5), 822.

Digman, J. M. (1997). Higher-order factors of the Big Five. Journal of Personality and Social Psychology, 73(6), 1246.

Dixon, M. L., Fox, K. C., \& Christoff, K. (2014). A framework for understanding the relationship between externally and internally directed cognition. Neuropsychologia, 62, 321-330.

Driver, J., \& Vuilleumier, P. (2001). Perceptual awareness and its loss in unilateral neglect and extinction. Cognition, 79(1), 39-88.

Evans, D. E., \& Rothbart, M. K. (2007). Developing a model for adult temperament. Journal of Research in Personality, 41, 868-888.

Evans, D. E., \& Rothbart, M. K. (2008). Temperamental sensitivity: Two constructs or one? Personality and Individual Differences, 44(1), 108-118. 
Evans, D. E., \& Rothbart, M. K. (2009). A Two-Factor Model of Temperament. Personality and Individual Differences, 47(6), 565-570.

Feist, G. J. (1998). A meta-analysis of personality in scientific and artistic creativity. Pers Soc Psychol Rev, 2(4), 290-309.

Feist, G. J. (2010). The function of personality in creativity: The nature and nurture of the creative personality. In J. C. Kaufman \& R. J. Sternberg (Eds.), The Cambridge handbook of creativity (pp. 113-130). United States: Cambridge University Press.

Fink, A., \& Benedek, M. (2014). EEG alpha power and creative ideation. Neuroscience \& Biobehavioral Reviews, 44, 111-123.

Förster, J., \& Dannenberg, L. (2010). GLOMOsys: A systems account of global versus local processing. Psychological inquiry, 21(3), 175-197.

Friedman, R. S., Fishbach, A., Förster, J., \& Werth, L. (2003). Attentional priming effects on creativity. Creativity Research Journal, 15(2-3), 277-286.

Friedman, R. S., \& Förster, J. (2001). The effects of promotion and prevention cues on creativity. Journal of Personality and Social Psychology, 81(6), 1001.

Friedrich, F. J., Egly, R., Rafal, R. D., \& Beck, D. (1998). Spatial attention deficits in humans: a comparison of superior parietal and temporal-parietal junction lesions. Neuropsychology, $12(2), 193$.

Goff, K., \& Torrance, E. P. (2002). Abbreviated Torrance Test for Adults manual. Bensenvill, IL: Scholastic Testing Service.

Goldberg, L. R. (1993). The structure of phenotypic personality traits. American Psychologist, $48(1), 26$.

Goldsmith, H. H., Buss, A. H., Plomin, R., Rothbart, M. K., Thomas, A., Chess, S., . . McCall, R. B. (1987). Roundtable: what is temperament? Four approaches. Child Dev, 58(2), 505529.

Hennessey, B. A., \& Amabile, T. M. (2010). Creativity. Annu Rev Psychol, 61, 569-598.

Hintsa, T., Wesolowska, K., Elovainio, M., Strelau, J., Pulkki-Raback, L., \& KeltikangasJarvinen, L. (2016). Associations of temporal and energetic characteristics of behavior with depressive symptoms: A population-based longitudinal study within Strelau's Regulative Theory of Temperament. J Affect Disord, 197, 196-204.

Homberg, J. R., Schubert, D., Asan, E., \& Aron, E. N. (2016). Sensory processing sensitivity and serotonin gene variance: Insights into mechanisms shaping environmental sensitivity. Neurosci Biobehav Rev, 71, 472-483.

Ivry, R. B., \& Robertson, L. C. (1998). The two sides of perception. Cambridge, MA: MIT Press.

Jagiellowicz, J., Xu, X., Aron, A., Aron, E., Cao, G., Feng, T., \& Weng, X. (2010). The trait of sensory processing sensitivity and neural responses to changes in visual scenes. Social cognitive and affective neuroscience, 6(1), 38-47.

Johnson, J. A. (1994). Clarification of factor five with the help of the AB5C model. European Journal of Personality, 8(4), 311-334.

Jung-Beeman, M., Bowden, E. M., Haberman, J., Frymiare, J. L., Arambel-Liu, S., Greenblatt, R., . . . Kounios, J. (2004). Neural activity when people solve verbal problems with insight. PLoS Biol, 2(4), e97.

Kagan, J. (2018). Perspectives on two temperamental biases. Phil. Trans. R. Soc. B, 373(1744), 20170158. 
Kantor-Martynuska, J. (2012). "The Princess and the Pea" Suggestions for the Revision of Sensory Sensitivity in the Regulative Theory of Temperament. Journal of Individual Differences, 33(4), 237-247.

Kaufman, A. B., Kornilov, S. A., Bristol, A. S., Tan, M., \& Grigorenko, E. L. (2010). The neurobiological foundation of creative cognition. In J. C. K. R. J. Sternberg (Ed.), The Cambridge handbook of creativity (pp. 216-232). New York, NY: Cambridge Univesity Press.

Kaufman, J. C., \& Sternberg, R. J. (Eds.). (2010). The Cambridge handbook of creativity. New York: Cambridge University Press.

Kaufman, S. B., Quilty, L. C., Grazioplene, R. G., Hirsh, J. B., Gray, J. R., Peterson, J. B., \& DeYoung, C. G. (2016). Openness to Experience and Intellect Differentially Predict Creative Achievement in the Arts and Sciences. J Pers, 84(2), 248-258.

Kaufmann, G. (2003). Expanding the mood-creativity equation. Creativity Research Journal, 15, 131-135.

Klimesch, W., Doppelmayr, M., Russegger, H., Pachinger, T., \& Schwaiger, J. (1998). Induced alpha band power changes in the human EEG and attention. Neuroscience letters, 244(2), 73-76.

Kline, R. B. (2015). Principles and practice of structural equation modeling: Guilford publications.

Knight, R. (1996). Contribution of human hippocampal region to novelty detection. Nature, 383(6597), 256-259.

Kounios, J., Fleck, J. I., Green, D. L., Payne, L., Stevenson, J. L., Bowden, E. M., \& JungBeeman, M. (2008). The origins of insight in resting-state brain activity. Neuropsychologia, 46(1), 281-291.

Kozbelt, A., Beghetto, R. A., \& Runco, M. A. (2010). Theories of creativity. The Cambridge handbook of creativity, $20,47$.

Licht, C. L., Mortensen, E. L., \& Knudsen, G. M. (2011). Association between Sensory Processing Sensitivity and the 5-HTTLPR Short/Short Genotype. Biological Psychiatry, 69, 152S-153S (Supplement for Society of Biological Psychiatry Convention and Annual Meeting, abstract, 510).

Lin, W.-L., Hsu, K.-Y., Chen, H.-C., \& Chang, W.-Y. (2013). Different attentional traits, different creativities. Thinking Skills and Creativity, 9, 96-106.

Lionetti, F., Aron, A., Aron, E. N., Burns, G. L., Jagiellowicz, J., \& Pluess, M. (2018). Dandelions, tulips and orchids: evidence for the existence of low-sensitive, mediumsensitive and high-sensitive individuals. Translational Psychiatry, 8(1), 24.

Lubart, T. I. (2001). Models of the creative process: Past, present and future. Creativity Research Journal, 13(3-4), 295-308.

Martindale, C. (1977). CREATIVITY, CONSCIOUSNESS, AND CORTICAL AROUSAL. Journal of Altered States of Consciousness, 3(1), 69-87.

Martindale, C. (1989). Personality, situation, and creativity. In J. A. Glover, R. R. Ronning, \& C. R. Reynolds (Eds.), Handbook of creariuity (pp. 211-232). New York: Plenum.

Martindale, C. (1999). Biological bases of creativity. In R. J. Sternberg (Ed.), Handbook of Creativity (pp. 137-152). Cambridge, UK: Cambridge University Press.

Martindale, C., Anderson, K., Moore, K., \& West, A. N. (1996). Creativity, oversensitivity, and rate of habituation. Personality and Individual Differences, 20(4), 423-427. 
Martindale, C., \& Armstrong, J. (1974). Relationship of creativity to cortical activation and its operant control. Journal of Genetic Psychology, 124(2), 311-320.

McCrae, R. R. (1987). Creativity, divergent thinking, and openness to experience. Journal of Personality and Social Psychology, 52(6), 1258.

McCrae, R. R., \& Costa, P. T. (1987). Validation of the five-factor model of personality across instruments and observers. Journal of Personality and Social Psychology, 52(1), 81.

McCrae, R. R., \& Costa, P. T. (1997). Conceptions and correlates of openness to experience. In R. Hogan, J. A. Johnson, \& S. R. Briggs (Eds.), Handbook of personality psychology (pp. 825-847). Orlando, FL: Academic Press.

Moore, S. R., \& Depue, R. A. (2016). Neurobehavioral foundation of environmental reactivity. Psychol Bull, 142(2), 107-164.

Necka, E., \& Hlawacz, T. (2013). Who has an Artistic Temperament? Relationships Between Creativity and Temperament Among Artists and Bank Officers. Creativity Research Journal, 25(2), 182-188.

Plucker, J. A., Beghetto, R. A., \& Dow, G. T. (2004). Why isn't creativity more important to educational psychologists? Potentials, pitfalls, and future directions in creativity research. Educational psychologist, 39(2), 83-96.

Pluess, M. (2015a). Individual Differences in Environmental Sensitivity. Child development perspectives, $9(3)$.

Pluess, M. (2015b). Vantage Sensitivity: Environmental Sensitivity to Positive Experiences as a Function of Genetic Differences. J Pers.

Posner, M. I. (1980). Orienting of attention. Quarterly journal of experimental psychology, $32(1), 3-25$.

Posner, M. I., \& Rothbart, M. K. (2007). Research on attention networks as a model for the integration of psychological science. Annu Rev Psychol, 58, 1-23.

Rothbart, M., Derryberry, D., \& Posner, M. (1994). A psychobiological approach to the development of temperament. Temperament: Individual differences at the interface of biology and behavior, 83-116.

Rothbart, M. K. (2007). Temperament, development, and personality. Current Directions in Psychological Science, 16(4), 207-212.

Rothbart, M. K., Ahadi, S. A., \& Evans, D. E. (2000). Temperament and personality: origins and outcomes. J Pers Soc Psychol, 78(1), 122-135.

Runco, M. A. (1998). Suicide and creativity: the case of Sylvia Plath. Death Stud, 22(7), 637654.

Runco, M. A. (2014). Creativity: Theories and Themes: Research, Development, and Practice (Second ed.): Elsevier, Inc.

Runco, M. A., \& Jaeger, G. J. (2012). The standard definition of creativity. Creativity Research Journal, 24(1), 92-96.

Runco, M. A., Plucker, J. A., \& Lim, W. (2000-2001). Development and psychometric integrity of a measure of ideational behavior. Creativity Research Journal, 13(3 \& 4), 393-400.

Rusalov, V., \& Trofimova, I. (2007). Structure of temperament and its measurement. PSP: Psychological Services Press Toronto.

Rusalov, V. M. (1989). [The natural prerequisites of individual behavior as a factor in the formation of human individuality]. Zh Vyssh Nerv Deiat Im I P Pavlova, 39(3), 403-414. 
Rusalov, V. M., \& Poltavtseva, L. I. (1997). [Temperament as a prerequisite of creative capabilities]. Zh Vyssh Nerv Deiat Im I P Pavlova, 47(3), 451-460.

Sawyer, R. K. (2012). Explaining creativity: The science of human innovation (Second ed.). New York: Oxford University Press, Inc.

Schooler, J. W., \& Melcher, J. (1995). The ineffability of insight. The creative cognition approach ( Cambridge, MA, US: The MIT Press), (pp. 97-133).

Shamay-Tsoory, S. G., Adler, N., Aharon-Peretz, J., Perry, D., \& Mayseless, N. (2011). The origins of originality: the neural bases of creative thinking and originality. Neuropsychologia, 49(2), 178-185.

Shiner, R. L., Buss, K. A., McClowry, S. G., Putnam, S. P., Saudino, K. J., \& Zentner, M (2012). What Is Temperament Now? Assessing Progress in Temperament Research on the Twenty-Fifth Anniversary of Goldsmith et al. (). Child development perspectives, 6(4), 436-444.

Shiner, R. L., \& DeYoung, C. G. (2013). The Structure of Temperament and Personality Traits: A Developmental. In P. D. Zelazo (Ed.), The Oxford Handbook of Developmental Psychology, Vol. 2: Self and Other (Vol. 2, pp. 113). New York: New York: Oxford University Press, Inc.

Silvia, P. J., Nusbaum, E. C., Berg, C., Martin, C., \& O’Connor, A. (2009). Openness to experience, plasticity, and creativity: Exploring lower-order, high-order, and interactive effects. Journal of Research in Personality, 43(6), 1087-1090.

Silvia, P. J., Winterstein, B. P., Willse, J. T., Barona, C. M., Cram, J. T., Hess, K. I., . . Richard, C. A. (2008). Assessing creativity with divergent thinking tasks: Exploring the reliability and validity of new subjective scoring methods. Psychology of Aesthetics, Creativity, and the Arts, 2(2), 68.

Simonton, D. K. (2012). Quantifying creativity: can measures span the spectrum? Dialogues Clin Neurosci, 14(1), 100-104.

Simonton, D. K. (2016). Defining Creativity: Don't We Also Need to Define What Is Not Creative? The Journal of Creative Behavior, 1-15.

Smith, S. M., Ward, T. B., \& Finke, R. A. (1995). The creative cognition approach.

Smolewska, K. A., McCabe, S. B., \& Woody, E. Z. (2006). A psychometric evaluation of the Highly Sensitive Person Scale: The components of sensory-processing sensitivity and their relation to the BIS/BAS and "Big Five". Personality and Individual Differences, $40,1269-1279$.

Sobocko, K., \& Zelenski, J. M. (2015). Trait sensory-processing sensitivity and subjective wellbeing: Distinctive associations for different aspects of sensitivity. Personality and Individual Differences, 83, 44-49.

Sokolov, E. N. (1963). Higher nervous functions: The orienting reflex. Annual review of physiology, 25(1), 545-580.

Sokolov, E. N. (1990). The orienting response, and future directions of its development. Integrative Physiological and Behavioral Science, 25(3), 142-150.

Strelau, J. (1998). Temperament: A Psychological Perspective. New York: Plenum Press.

Strelau, J., \& Zawadzki, B. (1993). The Formal Characteristics of Behavior-Temperament Inventory (FCB-TI): Theoretical assumptions and scale construction. European Journal of Personality, 7, 207-229. 
Strelau, J., \& Zawadzki, B. (1995). The formal characteristics of behaviour - temperament inventory (FCB-TI): Validity studies. European Journal of Personality, 9(3), 207-229.

Takeuchi, H., Taki, Y., Hashizume, H., Sassa, Y., Nagase, T., Nouchi, R., \& Kawashima, R. (2011). Failing to deactivate: the association between brain activity during a working memory task and creativity. Neuroimage, 55(2), 681-687.

Trofimova, I. (2010). An investigation into differences between the structure of temperament and the structure of personality. The American journal of psychology, 123(4), 467-480.

Trofimova, I. (2014). Observer bias: an interaction of temperament traits with biases in the semantic perception of lexical material. PLoS One, 9(1), e85677.

Trofimova, I. (2018). Functionality versus dimensionality in psychological taxonomies, and a puzzle of emotional valence. Philos Trans $R$ Soc Lond B Biol Sci, 373(1744).

Trofimova, I., \& Robbins, T. W. (2016). Temperament and arousal systems: A new synthesis of differential psychology and functional neurochemistry. Neurosci Biobehav Rev, 64, 382402.

Trofimova, I., Robbins, T. W., Sulis, W. H., \& Uher, J. (2018). Taxonomies of psychological individual differences: biological perspectives on millennia-long challenges. Philos Trans $R$ Soc Lond B Biol Sci, 373(1744).

Vatansever, D., Manktelow, A., Sahakian, B. J., Menon, D. K., \& Stamatakis, E. A. (2018). Default Mode Network Engagement Beyond Self-Referential Internal Mentation. Brain Connect.

Vatansever, D., Menon, D. K., Manktelow, A. E., Sahakian, B. J., \& Stamatakis, E. A. (2015). Default Mode Dynamics for Global Functional Integration. J Neurosci, 35(46), 1525415262.

Volf, N. V., Kulikov, A. V., Bortsov, C. U., \& Popova, N. K. (2009). Association of verbal and figural creative achievement with polymorphism in the human serotonin transporter gene. Neurosci Lett, 463(2), 154-157.

Volf, N. V., Sinyakova, N. A., Osipova, L. P., Kulikova, A. V., \& Belousova, L. V. (2015). Association between intelligence quotient and the 5HTTLPR polymorphism of human serotonin transporter coding gene. Annals of Neuroscience and Psychology, 2(6).

Wallas, G. (1926). The Art of Thought. New York: Franklin Watts. 